\title{
From Lyme disease emergence to endemicity: a cross sectional comparative study of risk perceptions in different populations
}

Cécile Aenishaenslin ${ }^{1 *}$, André Ravel ${ }^{1}$, Pascal Michel ${ }^{1,2}$, Lise Gern $^{3}$, François Milord ${ }^{4}$, Jean-Philippe Waaub ${ }^{5}$ and Denise Bélanger ${ }^{1}$

\begin{abstract}
Background: Lyme disease (LD) is a tick-borne emerging disease in Canada that has been endemic in many temperate countries for decades. Currently, one of the main approaches for LD prevention is the promotion of individual-level preventive behaviors against ticks. Health behaviors are influenced by individual and social factors, one important of which is risk perception. This study aims to describe and compare risk perception of LD, within and between general populations and experts living in two different regions: the Neuchâtel canton in Switzerland, where LD is endemic, and the Montérégie region in Québec (Canada), where LD is emerging.
\end{abstract}

Method: A web-based survey was conducted in both study regions (814 respondents) in 2012, and a questionnaire was administered to 16 experts. Comparative analyses of knowledge, risk exposure and different components of LD risk perception were performed. Multivariate analyses were used to calculate a global risk perception score and to identify determinants of risk perception in both regions.

Results: In Montérégie, only 15\% of the survey respondents had a good level of knowledge of LD compared to Neuchâtel where $51 \%$ of survey respondents had good levels of knowledge. In Montérégie, 24\% of respondents perceived themselves as being at high or very high risk of contracting LD vs 54\% in Neuchâtel; however, a higher percentage of respondents from this region believed that personal protection was simple to carry out (73\% vs 58\% in Montérégie). Based on the population surveys, almost all of the identified determinants of risk perception were different between both populations except for gender. A good level of knowledge, living in the risk zone and knowing someone who has had LD increased risk perception, while a high level of education and being 18-34 years of age decreased this perception. The majority of the studied components of risk perception were different between populations and their regional experts.

Conclusion: This study suggests that risk perception of LD differs between populations and regional experts living in different epidemiological situations. Monitoring of knowledge and risk perception in local populations may help to better target LD communication efforts in accordance with population specific attributes thereby enhancing prevention efficacy.

Keywords: Lyme disease, Lyme borreliosis, Risk perception, Prevention, Preventive behaviors, Knowledge, Emergence, Endemicity, General public, Experts

\footnotetext{
* Correspondence: cecile.aenishaenslin@umontreal.ca

${ }^{1}$ Groupe de Recherche en Épidémiologie des Zoonoses et Santé Publique (GREZOSP), Pavillon de la santé publique, Faculté de médecine vétérinaire, Université de Montréal, CP 5000, Saint-Hyacinthe J2S 7C6, Québec, Canada Full list of author information is available at the end of the article
} 


\section{Background}

Lyme disease (LD), or Lyme borreliosis, is the most frequent vector-borne disease in temperate countries [1]. In most cases, the disease causes non-specific flu-like symptoms and a typical skin lesion known as erythema migrans. More severe systemic infections can occur in some cases, and may lead to arthritis, cardiac and neurological problems [2]. With a recent adjusted estimation of about 300,000 human cases annually in the United States [3] and about 85,000 cases in Europe [1], Lyme disease is a growing concern in many countries, including Canada where it is currently emerging. In the province of Québec (Canada), locally acquired cases were first identified in 2008 [4]. Populations of black-legged ticks (Ixodes scapularis), the only known vector of Lyme disease on the eastern-American coast, are now recognized as established in the southern part of the province, in the Montérégie region. In this region, $8-13 \%$ of the black-legged ticks have been found to be infected with Borrelia burgdorferi, the bacteria causing LD [5]. In Switzerland, LD cases have been reported for more than 30 years [6]. The disease has not been notifiable since 2003, but current estimates place this country third highest for LD incidence in Europe with 83 cases per 100,000 inhabitants reported in 2010 [7]. In this country, Ixodes ricinus is the vector responsible for the transmission of LD, and prevalence of Borrelia burgdorferi infection in ticks is as high as $40 \%$ in some regions [8]. Moreover, in several regions of the country, these ticks are known to carry tick-borne encephalitis virus (TBEV), the agent of tick-borne encephalitis (TBE), another severe and notifiable disease in Switzerland [9].

Although LD ecology differs in Europe and North America with regards to the importance of different reservoir species of the bacteria and the primary tick vector involved in transmission [10], the main preventive strategy is the same in both regions and relies primarily on individual-level preventive behaviors [11]. Preventive behaviors such as checking for ticks after visiting affected wooded regions, wearing long trousers or repellent containing DEET, have been shown to be efficient in the prevention of LD [12-18]. However, beyond their demonstrated efficacy, studies have also shown that people do not apply these measures with the same consistency, even in highly prevalent regions [19-29].

Predictors of individual-level preventive behaviors have been studied for many health conditions. The Health Belief Model is one widely used theoretical model developed to study health behaviors. In this model, one main determinant of a health behavior is the perception of risk, defined as the subjective assessment of the probability and the consequences of a specified type of hazard [30]. Risk perception is composed of the perceived severity of and the perceived susceptibility to the disease in question [31].
This model has been validated for many diseases and health conditions including LD, for which a higher level of risk perception was associated with an increased adoption of preventive behaviors [19,28,29,32-34]. As a result, risk perception has become a major point of interest for decision-makers involved in the design and the implementation of preventive communication programs. An extensive literature exists on risk perception, Paul Slovic being a pioneer of the psychometric approach, which recognizes that risk perception is a construct reflecting individual and social level influences [35-37]. Studies have shown tendencies which seem to persist among different fields of research: the perceived risk in the general public differs from the risk as perceived (or evaluated) by experts [38]; determinants of risk perception are numerous and multidimensional, and they include characteristics of the hazard in question such as the novelty of the hazard and its potential catastrophic impacts, as well as individual and sociological factors, such as gender, age, education, income, personality, culture and values [35,39-41].

Past studies have described LD risk perception in particular regions or countries [19,21,22,25,27-29,32], but none have explored the differences between the determinants of risk perception in different epidemiological contexts, such as in a population experiencing the emergence of $L D$ versus a population that has been living in a region endemic for LD during a long period of time. Are determinants of LD risk perception universal, or do they vary according to the context, such as the epidemiologic situation? The identification of context-specific determinants of LD risk perception would provide additional insights for decision-makers in the planning of LD risk communication that could be better adapted to emerging or endemic situations. Moreover, it could help decisionmakers in emerging contexts to anticipate the changes in their population's risk perception that may occur once LD becomes endemic.

With this perspective in mind, the main objective of this study was to compare risk perception of LD and to describe its determinants within and between two different populations: residents of the Neuchâtel canton, in Switzerland where LD has been endemic for more than 30 years, and residents of the Montérégie region, in Québec, Canada, where LD is emerging and where the indigenous cases were first reported in 2008. A second objective was to compare perceptions of the general population with perceptions of regional LD experts, and between experts from both regions. Estimated LD incidence in the Neuchâtel canton ranged from 49 to 95 cases per 100,000 inhabitants by 1996-2001 [42,43], which was above the national mean incidence for Switzerland. Montérégie had an estimated incidence of 0.5 cases per 100,000 inhabitants in 2012, making it the most affected region in the province of Québec (Canada) [44]. 


\section{Methods}

\section{Study design}

This cross sectional study was based on a web survey that was administered simultaneously in the fall of 2012 in the two study regions. The questionnaire, which included 58 questions, was constructed for the purposes of this study and was based on the theories of health behaviors [31] and on existing questionnaires measuring LD knowledge, attitudes and behaviors [45,46]. Questions were designed to measure perceptions of LD: perceived severity, perceived individual susceptibility, perceived susceptibility for other residents in the region (perceived regional susceptibility), perceived personal control on LD prevention (perceived mastery), perceived scientific uncertainty (perceived uncertainty), perceived confidence in preventive public programs, feeling of worry, perceptions of the efficacy of preventive individual-level and environmentallevel measures, and social acceptability of preventive environmental measures. Moreover, LD knowledge (four items were evaluated: knowledge related to the transmission mode, early symptoms, treatment, risk zone), frequency of exposure through outdoor activities (used as an indicator of the level of exposure), past experiences with LD (knowing someone with LD or having had LD before), adoption of individual preventive behaviors and sociodemographic characteristics (gender, age, education, family income, geographic location of residency) were also included. Questions pertaining to perception were evaluated using a five point Likert scale: (5) strongly agree, (4) agree, (3) neither agree nor disagree, (2) disagree, (1) strongly disagree. In order to allow participants with no knowledge of LD to complete the questionnaire, all participants were given a short informative text providing general basic information about LD as provided by government websites in both regions (excluding the knowledge questions which were administered before this reading and only to those having declared that they had previously heard of LD). The questionnaire and the descriptive text accompanying it were adapted for the Canadian and Swiss contexts. The general content of the questionnaires was the same for both regions; however, the exact wording of some questions was adapted to account for cultural differences, such as family income and education levels, and for three specific items which were added to the Neuchâtel questionnaire: the perceived knowledge of Tick-Borne encephalitis (TBE), the perceived knowledge of differences between $\mathrm{LD}$ and TBE, and the district of residency. There are six districts in the Neuchâtel region: three of the districts (Neuchâtel, Boudry, Val-de-Ruz) are at a higher risk of LD (low altitude) compared to the other three districts (Val-de-travers, Le Locle, La-Chaux-de-Fond) considered to be at lower risk due to their location at higher altitudes where tick densities are lower $[43,47]$. The questionnaire was designed to study perceptions, attitudes and preventive behaviors in a global perspective. This paper will focus on knowledge, risk perception and its determinants.

The questionnaire was developed and administered in French, which is the main language of both the Montérégie and Neuchâtel regions. It was pre-tested to verify the formulation of questions and general understanding with 35 people from the general public through focus groups conducted between August $12^{\text {th }}$ and September $30^{\text {th }} 2012$ in both regions. This protocol was reviewed and approved by the Ethical Committee for Health Research of the University of Montreal (CERES).

\section{Data collection}

In each region, the questionnaire was administered to a random sample of members of a web panel. The panels used in this study are administered by the external survey firm Leger Marketing [48]. They include individuals from the general population who had engaged either voluntarily with the panel or had been recruited through probabilistic phone surveys by the firm in order to be representative of each region in terms of socio-demographic factors including gender, age, education, income and geographic distribution. These panels are used to complete surveys on a large variety of subjects which are not related to Lyme disease including research, marketing studies and opinion polls and are a good representation of the general public for our study object. In order to reach a sample size of 400 participants in each region, the invitation to participate was sent to two subsamples of the regional web panels, for a total of 5,222 people in Montérégie and of 1,233 people in Neuchâtel, which represent respectively $0.4 \%$ and $0.7 \%$ of the total population $[49,50]$. Inclusion criteria were: to be 18 years of age or older, to be a resident of one of the two study regions and to understand French. The survey was available online from November $19^{\text {th }}$ to December $1^{\text {st }}$ 2012 in Neuchâtel and from November $19^{\text {th }}$ to November $22^{\text {nd }} 2012$ in Montérégie (it was closed when 400 respondents had completed it).

Another questionnaire was designed for experts using a subset of questions from the main questionnaire in order to measure risk perception, perceptions of the efficacy of individual and environmental level preventive measures, and perceived acceptability of environmental measures. Experts were selected based on their involvement in LD management. In Montérégie, seven experts were invited to complete the questionnaire and were those who had previously participated in a study for LD management in Québec [51]. In Neuchâtel, nine experts were invited and represented members of the National Reference Centre for tick-transmitted diseases [52]. The expert questionnaires were sent by e-mail and the response period for both regions was between August $12^{\text {th }}$ and September $30^{\text {th }} 2012$. 


\section{Data analysis}

Statistical analyses were stratified for each study region and performed using IBM SPSS Statistics 19. Confidence intervals for proportions were computed using the ClopperPearson method with a confidence level of 95\% [53]. Pearson Chi-square statistics were performed to detect significant differences $(\mathrm{p}<0.05)$ between groups (study regions, gender, age groups). A global knowledge score (null, medium, high) was developed based on the four items assessed (for a maximum of four possible good answers): (null $(0=$ no good answer), medium $(1=1$ or 2 good answers) and high ( $2=3$ or 4 good answers)). Participants who declared that they have never heard about LD before the survey were automatically given 0 for this score.

To allow for descriptive comparisons, mean scores, modes and ranges were calculated for a selection of perception variables for both the population and for the expert surveys. Statistical differences between mean population scores were tested using the Student's t test for independent samples with $\mathrm{p}<0.05$.

In order to select the most important perception variables and be able to summarize them in a global risk perception score for each participant, an exploratory factor analysis (EFA) [54] was performed and initially included seven risk perception variables (perceived severity, perceived individual susceptibility, perceived regional susceptibility, perceived mastery, perceived uncertainty, perceived confidence, feeling of worry). Factor extraction was performed using the unweighted least squares method (recommended for ordinal data) and an oblique rotation (recommended for psychosocial measures) [55,56]. EFA necessitates that a sufficient correlation exist between variables that are included in the analysis. Therefore, variables with an initial quality of representation inferior to 0.2 (i.e. the part of the variable variance that can be explained by all other variables) were excluded from the analysis. Factors with eigenvalues under 1 were not considered. Selected variables were those with factor loadings on the perception factor that were superior to 0.5. A Kaiser-Meyer-Olkin measure of sampling adequacy was calculated for both regions [57]. For each participant, a global risk perception score was then calculated as the mean score of the selected variables based on the results of the factor analysis. Cronbach alpha was calculated using the selected perception variables on the total sample, as an indicator of the internal consistency of the perception measures [58].

Linear multivariate regressions were then performed separately for the two regional subsets using the global risk perception score as the dependant variable. Multivariate analyses were stratified by region because we anticipated that predictors of risk perception would be different in both contexts. Univariate regressions were done separately for each independent variable (age, gender, household income, education level, general knowledge about LD, region of residency, individual frequency of exposure in public area, personal history with LD, history with LD in relatives) and variables associated with the dependant variable with $\mathrm{p}<0.20$ were included in the initial multivariate models. Reduced final models were selected using a backward elimination process with $\mathrm{p}<0.05$. After the identification of significant predictors in each separate region, these were forced in the other region's model as independent variables, even if not significant, in order to allow proper comparisons of the coefficients between populations.

\section{Results}

\section{Sample description}

A total of 814 participants completed the questionnaire (401 in Montérégie and 413 in Neuchâtel), for a combined response rate of $14 \%$. In Montérégie, 199 (50\%) participants were women, 191 (48\%) were 55 years old or more, 168 (42\%) had a level of education equivalent to college and 135 (34\%) had a family income between 40,000 and 79,999 \$CAN. In Neuchâtel, 241 (58\%) participants were women, 112 (27\%) were 55 years old or more, 209 (51\%) had a college level of education and 139 (34\%) had a family income between 40,000 and 79,999 CHF (Table 1). The distribution of these socio-demographic characteristics were similar to the underlying populations when compared to regional census data $[49,50]$.

\section{Past history with LD, exposure and knowledge}

In Montérégie, 185 (46\%) participants declared that they have never heard of LD before the survey, 14 (4\%) knew someone who had contracted LD and $3(1 \%)$ declared that they had previously had LD compared to 89 (22\%), $168(41 \%)$ and $24(6 \%)$ of participants respectively in the Neuchâtel region (proportions are all significantly different between regions with $\mathrm{p}<0.0001$; Table 2 ).

In Neuchâtel, 51\% (211/413) of participants declared having had a high-level of exposure (10 or more outdoor activities in a LD risk region during the risk period), compared to $17 \%(69 / 401)$ in Montérégie, which is significantly lower $(\mathrm{p}<0.0001)$ (Table 2$)$. In Neuchâtel, highly exposed respondents were primarily women (120/211, $57 \%)$, aged $35-54$ years old $(93 / 211,44 \%)$, with a high level of knowledge of LD (124/211, 59\%), whereas in Montérégie, men were the most highly exposed group $(44 / 69,64 \%)$, aged $35-54$ (33/69, 48\%), with only $17 \%$ (12/69) reporting a high level of LD knowledge.

The proportion of respondents with a high level of knowledge of LD was significantly higher in Neuchâtel with $51 \%(209 / 413)$ compared to $15 \%(60 / 401)$ in Montérégie $(\mathrm{p}<0.0001)$. Proportions of good answers on the four knowledge questions ranged from 44 to $65 \%$ in Neuchâtel, and from 18 to $29 \%$ in Montérégie (Table 2), the most commonly failed questions being on LD treatment and 
Table 1 Sociodemographic description of the 814 participants by study region

\begin{tabular}{|c|c|c|}
\hline & $\begin{array}{c}\text { Montérégie } \\
\text { n (\%) }\end{array}$ & $\begin{array}{c}\text { Neuchâtel } \\
\text { n (\%) }\end{array}$ \\
\hline Total & $401(100)$ & $413(100)$ \\
\hline \multicolumn{3}{|l|}{ Gender } \\
\hline Women & $199(50)$ & $241(58)$ \\
\hline Men & $202(50)$ & $172(42)$ \\
\hline \multicolumn{3}{|l|}{ Age } \\
\hline $18-34 \mathrm{yr}$ & $57(14)$ & $110(27)$ \\
\hline $35-54 \mathrm{yr}$ & $153(38)$ & $191(46)$ \\
\hline $55+y r$ & $191(48)$ & $112(27)$ \\
\hline \multicolumn{3}{|l|}{ Education level } \\
\hline High school or less & $113(28)$ & $28(7)$ \\
\hline College or equivalent & $168(42)$ & $209(51)$ \\
\hline University or equivalent & $112(28)$ & $170(41)$ \\
\hline$n a^{*}$ & $8(2)$ & $6(1)$ \\
\hline \multicolumn{3}{|c|}{ Household income (\$CAN or CHF) } \\
\hline$<40000$ & $83(21)$ & $54(13)$ \\
\hline $40000-79999$ & $135(34)$ & $139(34)$ \\
\hline 80 000-119999 & $88(22)$ & $103(25)$ \\
\hline$>$ or $=120000$ & $29(7)$ & $43(10)$ \\
\hline$n a^{*}$ & $66(17)$ & $74(18)$ \\
\hline
\end{tabular}

*Prefer not to answer.

knowledge of risk zones. Figure 1A presents the proportions of participants with high levels of knowledge by gender and age group. In Neuchâtel, globally, high-levels of knowledge was more frequent in women (136/241 or 56\% vs $73 / 172$ or $42 \%$ in men, $\mathrm{p}=0.005)$ with the greatest disparities in the group of $35-54$ year olds $(73 / 122$ or $60 \%$ for women $v s 24 / 69$ or $35 \%$ for men). In men, the proportion was higher in the $55+$ yr olds $v s$ other age groups $(p=0.01)$. There was no significant difference between age groups in women. In Montérégie, the proportion of respondents with a high-level of knowledge remained low within gender and age groups with no significant differences $(\mathrm{p} \geq 0.05)$ (Figure 1$)$.

\section{Risk perception within and between regions}

Globally, the proportion of respondents with a high level of risk perception (\% of respondents with scores of 4 or 5 ) was greater in Neuchâtel for all perception variables, except for the perceived severity (Table 2). The proportion of respondents with high-perceived mastery was also higher in Neuchâtel (73\% or $301 / 413$ vs $58 \%$ or $231 / 401$ in Montérégie, $\mathrm{p}<0.001$ ). Within both populations, the proportions of respondents with high scores for the perceived individual susceptibility, the perceived regional susceptibility, the perceived severity and for feeling of worry varied according to gender and age groups (Figure 1, B, C,
D and E). In both regions, proportions were significantly greater in women for all of these items $(\mathrm{p}<0.05)$, except for feeling of worry in Montérégie. In Montérégie, for all four variables, the proportion of respondents with high-perceived risks was different between age groups $(\mathrm{p}<0.05)$, while no significant difference was identified between age groups in Neuchâtel. In Neuchâtel, 23\% (95/413) of respondents declared that they had a good knowledge of the difference between TBE and LD (score of 4 or 5 on the agreement scale) and 18\% (75/413) had never heard about TBE.

Considering central tendencies, the mode was consistent between regions for four perception variables: the perceived regional susceptibility $($ mode $=4)$, the perceived severity (mode $=4)$, the perceived mastery $($ mode $=4)$ and the perceived confidence (mode $=3$ ), but differed for the perceived individual susceptibility (mode $=2$ in Montérégie vs 4 in Neuchâtel), the perceived uncertainty (mode $=4$ in Montérégie vs 3 in Neuchâtel) and feeling of worry (mode $=2$ in Montérégie vs 3 in Neuchâtel) (Table 3). Perceived individual susceptibility means were 2.7 in Montérégie and 3.4 in Neuchâtel, and were both smaller than the mean perceived regional susceptibility, which was equal to 3.1 and 3.6, respectively. All mean scores were significantly different between populations ( $\mathrm{p}<0.05$, Table 3 ).

\section{Risk perceptions in experts}

Except for the perceived regional susceptibility in Neuchâtel, the modes differed between populations and experts for all other measured perception variables (Table 3). With regards to inter-regional expert comparison, modes differed on three variables: the perceived regional susceptibility (experts mode $=2$ in Montérégie vs 4 in Neuchâtel), the perceived uncertainty (experts mode $=2$ in Montérégie vs 4 in Neuchâtel) and the perceived confidence (experts mode $=2$ in Montérégie vs 4 in Neuchâtel).

\section{Factor analysis and global risk perception score}

For both regional subsets, first EFA led to the exclusion of two variables with a quality of representation inferior to 0.2: perceived uncertainty and feeling of confidence (Table 4). Final EFA suggested the presence of one latent factor with an eigenvalue superior to 1 , with four main contributing variables: perceived individual susceptibility, perceived regional susceptibility, perceived severity and feeling of worry (perceived mastery was excluded because its factor loading on the factor was inferior to 0.5). These variables were the same for both regions, with factor loadings ranging from 0.51 to 0.80 in Montérégie and from 0.52 to 0.84 in Neuchâtel (Table 4). The Kaiser-Meyer-Olkin measure of sampling adequacy was 0.714 in Neuchâtel and 0.762 in Montérégie, which is considered as acceptable [57]. The final models explained $42.0 \%$ and $48.5 \%$ of variance in Neuchâtel and Montérégie, respectively. Cronbach alpha for the four variables was 0.760 which is considered 
Table 2 Descriptive analysis of past history with LD, exposure, knowledge and perceptions per region

\begin{tabular}{lcllll}
\hline & \multicolumn{2}{c}{ Montérégie } & & \multicolumn{2}{c}{ Neuchâtel } \\
& $\mathbf{n}$ & $\%(\mathrm{Cl})^{\mathbf{1}}$ & & $\mathbf{n}$ & $\%(\mathrm{Cl})^{\mathbf{1}}$ \\
\hline Total & 401 & & & 413 &
\end{tabular}

Past history with LD

Know someone with LD

Have ever had LD

Have a dog

Never heard about LD

Know LD for one year or less

Know LD for more than

one year

Exposure frequency through

outdoor activities

Less than 2 times per yr

2-10 times per yr

11-25 times per yr

More than 25 times per yr

Knowledge on LD

Transmission mode (Know that LD is transmitted by a tick bite)

Early symptom (Know that skin erythema is an early sign of LD)

Treatment (Know that LD can be treated with systemic

antibiotics)

Risk zone (Know where it is possible to contract LD in their region)

Global level of knowledge

High (\% with global score of 3 or 4 )

Medium (\% with global score of 1 or 2)

Null (\% with global score of 0)

Specific items related to TBE (Neuchâtel only)

Never heard about TBE

Know TBE for one year or less

Know TBE for more than

one year

Know well the differences

between TBE and LD

(self-declared \% of scores

4-5 on an agreement scale)

Risk perceptions (\% with score 4-5)

High-perceived individual susceptibility

High-perceived regional susceptibility

High-perceived severity of LD

$\begin{array}{cccc}14 & 3(2-6) & 168 & 41(36-46)^{*} \\ 3 & 1(0-2) & 24 & 6(4-9)^{*} \\ 83 & 21(17-25) & 74 & 18(14-22) \\ 185 & 46(41-51) & 89 & 22(18-26)^{*} \\ 42 & 10(8-14) & 48 & 12(9-15) \\ 174 & 43(38-48) & 276 & 67(62-71)^{*}\end{array}$

$174 \quad 43(38-48) \quad 276 \quad 67(62-71)^{*}$

$177 \quad 44(39-49) \quad 47 \quad 11(8-15)^{*}$

$155 \quad 39$ (34-44) $155 \quad 38(33-42)$

$41 \quad 10(7-14) \quad 97 \quad 23(19-28)^{*}$

$28 \quad 7(5-10) \quad 114 \quad 28(23-32)^{*}$

$11228(24-33) 270 \quad 65(61-70)^{*}$

$115 \quad 29(24-33) \quad 224 \quad 54(49-59)^{*}$

$71 \quad 18(14-22) \quad 182 \quad 44(39-49)^{*}$

$72 \quad 18(14-22) \quad 228 \quad 55(50-60)^{*}$

$60 \quad 15(12-19) \quad 209 \quad 51(46-56)^{*}$

$117 \quad 29(25-34) \quad 105 \quad 25(21-30)$

$22456(51-61) \quad 99 \quad 24(20-28)^{*}$ 


\section{Montérégie}

\section{A) High level of knowledge}

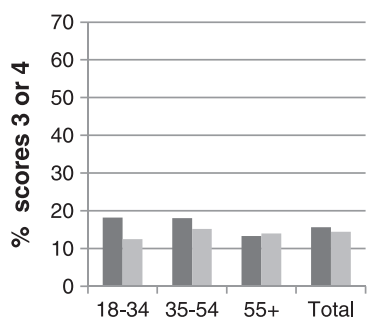

B) Perceived individual susceptibility

'Without any preventive measures, the risk that I contract Lyme disease in my region is high or very high'
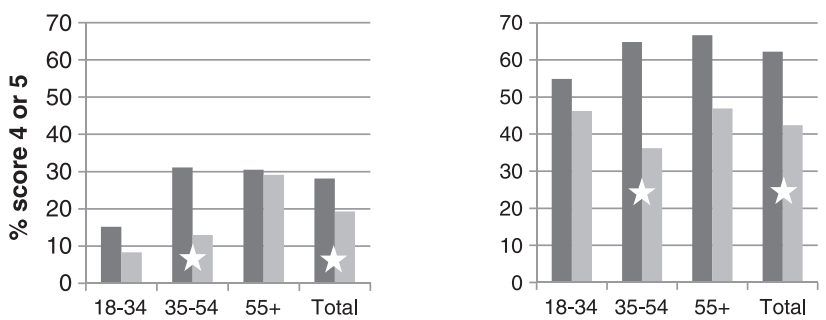

Women

Men

C) Perceived regional susceptibility

'Without any preventive measures, the risk that residents from my region contract Lyme disease is high or very high'
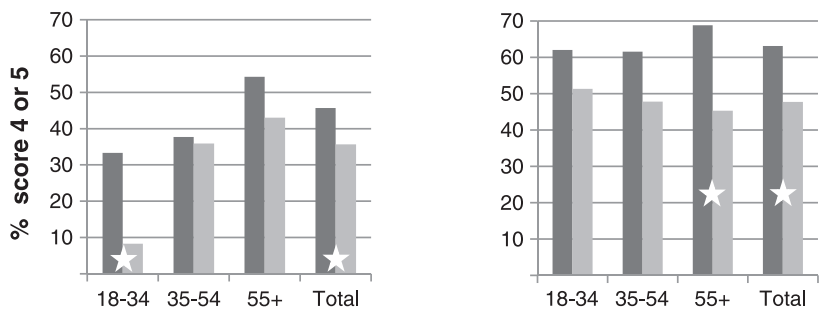

Women

Men

D) Perceived severity

'Lyme disease is a very severe disease'
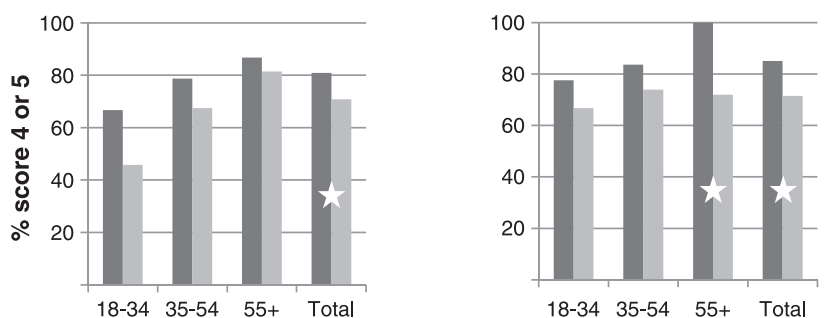

Women

Men

E) Feeling of worry

'I am worry by the idea of contracting Lyme disease'

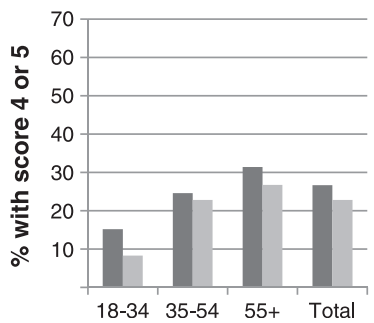

Figure 1 (See legend on next page.)

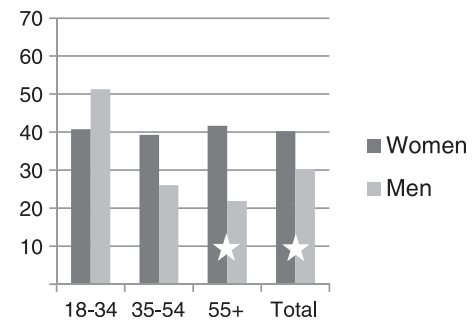


(See figure on previous page.)

Figure 1 Distribution of high levels of knowledge (A), perceived individual susceptibility (B), perceived regional susceptibility (C), perceived severity (D) and feeling of worry (E) in both regions, according to gender and age groups (dark gray represents proportions in women and light gray in men; stars represent significant differences in proportions between women and men in different age groups and globally).

Table 3 Comparison of mean scores and modes for seven perception's dimensions between the general population and their regional experts

\begin{tabular}{lccccc}
\hline & \multicolumn{2}{c}{ Montérégie } & & \multicolumn{2}{c}{ Neuchâtel } \\
\cline { 2 - 3 } & Population & 401 & Experts & Population & Experts \\
\hline Total & 413 & 9
\end{tabular}

Perceived individual susceptibility

Without any preventive measures. the risk that I contract Lyme disease in my region is high ${ }^{1}$

$\begin{array}{lccc}\text { Mean score } & 2.7 & - & 3.4^{* * *} \\ \text { Mode } & 2 & - & 4\end{array}$

Perceived regional susceptibility

Without any preventive measures, the risk to contract Lyme disease for residents is high

$\begin{array}{lcccc}\text { Mean score } & 3.2 & 1.9 & 3.6^{* * *} & 3.9 \\ \text { Mode (range) } & 4 & 2(1-3) & 4 & 4(2-5)\end{array}$

\section{Perceived severity}

Lyme disease is a very severe disease

$\begin{array}{lcccc}\text { Mean score } & 4.0 & 3.0 & 4.1^{*} & 3.7 \\ \text { Mode (range) } & 4 & 3(2-4) & 4 & 3(3-5)\end{array}$

\section{Perceived mastery}

It is easy to protect myself against Lyme disease

$\begin{array}{lcccc}\text { Mean score } & 3.6 & 4.9 & 3.9^{* * *} & 4.7 \\ \text { Mode (range) } & 4 & 5(4-5) & 4 & 5(4-5)\end{array}$

\section{Perceived uncertainty}

I have the feeling that there is great scientific uncertainty concerning Lyme disease

$\begin{array}{lcccc}\text { Mean score } & 3.3 & 2.7 & 2.7^{* * *} & 3.8 \\ \text { Mode (range) } & 4 & 2(2-4) & 3 & 4(3-5)\end{array}$

Feeling of worry

I am worry by the idea of contracting Lyme disease

$\begin{array}{lccc}\text { Mean score } & 2.7 & - & 3.0^{* * *} \\ \text { Mode } & 2 & - & 3\end{array}$

Feeling of confidence

I am confident that responsible authorities set up appropriate measures to control Lyme disease

$\begin{array}{lcccc}\text { Mean score } & 3.1 & 3 & 3.4^{* *} & 3.2 \\ \text { Mode (range) } & 3 & 2(2-5) & 3(2-4) \\ \text { Global risk perception score }{ }^{2} & & & 3.5^{* * *} & - \\ \text { Mean score } & 3.2 & - & 3.8\end{array}$

${ }^{1}$ All measurement scales are 1: strongly disagree, 2: disagree, 3: neither agree or disagree, 4: agree, 5: strongly agree.

${ }^{2}$ Global risk perception scores represent the mean score on: perceived individual susceptibility, perceived regional susceptibility, perceived severity of the disease and feeling of worry.

${ }^{*} \mathrm{p}<0.05 ;{ }^{* *} \mathrm{p}<0.01 ;{ }^{* * *} \mathrm{p}<0.001$ (Student $\mathrm{t}$ test). 
Table 4 Exploratory factor analysis of the perception variables

\begin{tabular}{|c|c|c|}
\hline & Montérégie & Neuchâtel \\
\hline \multicolumn{3}{|l|}{ Initial model } \\
\hline \multicolumn{3}{|l|}{$\begin{array}{l}\text { Quality of representation }{ }^{1} \text { of EFA with } \\
\text { seven variables (used for initial selection } \\
\text { of variables) }\end{array}$} \\
\hline Perceived individual susceptibility & 0.47 & 0.40 \\
\hline Perceived regional susceptibility & 0.66 & 0.67 \\
\hline Perceived severity & 0.27 & 0.30 \\
\hline Feeling of worry & 0.62 & 0.44 \\
\hline Perceived mastery & 0.22 & 0.34 \\
\hline Perceived confidence ${ }^{2}$ & 0.12 & 0.08 \\
\hline Perceived uncertainty ${ }^{2}$ & 0.04 & 0.07 \\
\hline \multicolumn{3}{|l|}{ Final model } \\
\hline Percentage of variance explained & 48.5 & 42.0 \\
\hline $\begin{array}{l}\text { Kaiser-Meyer-Olkin measure of } \\
\text { sampling adequacy }\end{array}$ & 0.762 & 0.714 \\
\hline \multicolumn{3}{|l|}{ Factor loadings of retained variables ${ }^{3}$} \\
\hline Perceived individual susceptibility & 0.67 & 0.63 \\
\hline Perceived regional susceptibility & 0.80 & 0.84 \\
\hline Perceived severity & 0.51 & 0.52 \\
\hline Feeling of worry & 0.76 & 0.54 \\
\hline Cronbach alpha (total sample) & \multicolumn{2}{|c|}{0.760} \\
\hline
\end{tabular}

${ }^{1}$ The quality of representation represents the variable variance that can be explained by all other variables.

${ }^{2}$ Variables excluded from the analysis (quality of representation inferior to 0.2 for both populations).

${ }^{3}$ Perceived mastery was excluded from the final model because its factor loading on the factor was inferior to 0.5 .
Neuchâtel residents declared themselves as more often exposed through outdoor activities than in Montérégie, which also reflects the fact that most people in this region live near (if not 'in') the tick inhabited regions. Accordingly, the mean global risk perception score was higher in Neuchâtel. This is consistent with previous findings comparing risk perception in low and high incidence states in the United States and showing that risk perception was positively correlated to incidence of LD [28,29].

Looking at the same results, we can also highlight that a lack of knowledge about the risks of LD still persists in Neuchâtel despite the high regional incidence: $22 \%$ of the respondents declared they had never heard about the disease, 35\% did not know that the disease was transmitted by a tick and three out of four did not know the difference between LD and TBE. A previous national study in the United States also reported that 7\% of people had never heard about LD in high-incidence States, and that 22\% declared that they did not know how LD is contracted [29]. These results suggest that living in an endemic area established for a long time does not guarantee that the entire population will be aware of the risks and have sufficient knowledge of how to protect themselves. This underscores the need to adjust, strengthen and maintain communication efforts about LD risks even as the epidemiological situation evolves over time.

Some surprising findings arose. First, the mode of the perceived regional susceptibility was found to be equal between regions even though the incidence was nearly 200 times higher in Neuchâtel compared to Montérégie for this period (95 vs 0.5/100,000). In Montérégie, the population perceived regional susceptibility was greater than the expert's perceived regional susceptibility, who most often consider the risk to be low in this region. One possible explanation for this observation could rest on the novelty of the hazard for the Montérégie

Table 5 Determinants of LD risk perception

\begin{tabular}{|c|c|c|c|c|}
\hline & \multicolumn{2}{|c|}{$\begin{array}{c}\text { Montérégie } \\
\mathrm{n}=392\end{array}$} & \multicolumn{2}{|c|}{$\begin{array}{c}\text { Neuchâtel } \\
n=406\end{array}$} \\
\hline & Coefficient & $95 \% \mathrm{Cl}$ & Coefficient & $95 \% \mathrm{Cl}$ \\
\hline Gender (Being a woman, man = reference category) & $0.25^{* * *}$ & $(0.1-0.39)$ & $0.26^{* * *}$ & $(0.11-0.40)$ \\
\hline \multicolumn{5}{|l|}{ Age } \\
\hline $18-34 \mathrm{yr}$ & $-0.52^{* * *}$ & $(-0.74--0.30)$ & -0.01 & $(-0.20-0.19)$ \\
\hline $35-54 \mathrm{yr}$ & $-0.16^{*}$ & $(-0.3-0.01)$ & 0.04 & $(-0.13-0.21)$ \\
\hline $55+$ yr (reference category) & 0 & & 0 & \\
\hline University diploma & $-0.18^{*}$ & $(-0.34--0.01)$ & -0.08 & $(-0.22-0.07)$ \\
\hline High level of general knowledge on LD & $0.37^{* * *}$ & $(0.18-0.57)$ & 0.07 & $(-0.09-0.22)$ \\
\hline Leaving in the higher risk area in Neuchâtel canton & - & - & $0.18^{*}$ & $(0.03-0.33)$ \\
\hline Knowing someone who had LD & 0.14 & $(-0.25-0.53)$ & $0.28^{* * *}$ & $(0.12-0.44)$ \\
\hline$r 2$ & 0.119 & & 0.108 & \\
\hline
\end{tabular}

${ }^{*} p<0.05 ; * * * p<0.001$. 
population. New threats frequently lead to higher perceived risk in the general population, as has been previously demonstrated in studies comparing risk perception between different kinds of hazards [35].

Second, Montérégie respondents rated the risk for themselves (mode $=2$, mean $=2.7$ ) and the risk for the residents of their region (mode $=4$, mean $=3.2$ ) differently. The underestimation of the personal risk as opposed to the general population risk has been described before for other hazards and is known as 'unrealistic optimism' [39]. Explanations for this optimism have been extensively studied before and are reviewed in Shepperd and colleagues [60]. In Neuchâtel, this phenomenon is not observed. One possible explanation is that past history with LD among respondents or their relatives is more prevalent in this region. Personal experiences with a hazard has been shown to decrease unrealistic optimism [61].

This study showed that the perceived risk of LD differed between the population and their regional experts. In Montérégie, experts rated the measured components of risk as smaller and more 'controllable' than the population. Many studies have demonstrated differences between public and expert risk perception for other hazards $[35,38,62]$ and this trend can be problematic when decisions have to be made about risk management options. Given that risk perception can affect the adoption of preventive behaviors, as well as the social acceptability of public health actions, our results suggest not only that risk perception of a hazard has to be taken into account when making such decisions, but also that risk perception should be measured directly in the target population, and cannot be extrapolated from studies carried out in different contexts, nor by regional experts. Because of the limited number of experts who participated in this study, statistical analysis could not be performed to compare perceptions between the population and experts and between both groups of experts.

One interesting aspect of this study lies in the use of EFA to build a global risk perception score for LD. Past studies of risk perception and LD have used individual perception variables such as the perceived susceptibility and the perceived severity of the disease as the dependant variable or as independent variables to predict preventive behaviors [25,28,29,32]. However, we hypothesised that risk perception is a complex construct that can only be imperfectly captured by individual survey questions. Most individual perception variables are correlated, and factor analysis can be used to verify the internal consistency of a set of questions designed to measure a construct (internal consistency) and to reduce the measurement bias related to individual questions by identifying which composition of items best represents a single factor (composite reliability) [63]. Although identifying determinants of a global perception score could be more interesting for public health decision-making than focusing on individual perception variables, the use of EFA has been criticized, mainly because of the absence of objective criteria to guide decisions necessary to complete the analysis, particularly in the choice of the type of rotation of factors [64]. In this study, no rotations were performed in the final model given that only one factor was retained. We used EFA to explore which perception variables to include in a global risk perception score and we interpreted the results in light of previous findings. The Health Belief Model recognizes two main dimensions of risk perception: the severity of the hazard and the susceptibility of individuals to this hazard [31]. Empirical studies have underlined that individual susceptibility can be perceived differently than the susceptibility for the general population [39]. These three dimensions (perceived severity, perceived individual susceptibility, perceived regional susceptibility) were identified in this study, along with feeling of worry, as the main contributors to a factor with the EFA realized in both populations and this strengthens the choice of these four variables in the construction of a global score.

Another important result of our study was the identification of different determinants of risk perception regarding LD in both populations, suggesting that the determinants may not be universal but rather context-dependant. The only common predictor was gender, a well-known determinant of risk perception. Possible explanations for gender differences in risk perception have been explored in the risk perception literature and include differences in social roles and activities [65]. In Montérégie, the effect of age was also highlighted, where being less than 35 years old decreased risk perception. This effect has been demonstrated before for other hazards, particularly regarding risk perception of road accidents [66]. One interesting finding is that in Neuchâtel, where the disease has been endemic for a long time, the level of knowledge was not significantly associated with risk perception, in contrast to the Montérégie region. It is both the exposure (living in a high risk region) and past history with LD that constituted the strongest predictors of risk perception. Only a handful of other studies have previously identified determinants of LD risk perception, being that the main focus of these other studies has generally been to identify predictors of the adoption of preventive behavior. Knowledge of LD [24], knowing someone who has had LD [24], the presence of tick populations [59], and cultural identity [21] have been identified before as factors that may affect risk perception of LD.

Globally, these results suggest that in populations facing an emerging threat such as LD in Montérégie, risk perception is mostly determined by globally available information. In the Montérégie context of LD emergence, risk perception seemed less affected by an individual's 
specific circumstance, i.e. their exposure and past history with $\mathrm{LD}$, than it was in the $\mathrm{LD}$ endemic region of Neuchâtel. This further suggests that the availability of reliable information becomes particularly important in a context of emergence. This comparison can provide useful insights for both Canadian and Swiss decision-makers, as well as for other countries facing a challenge of LD emergence. On the one hand, this study provides important information for local populations and on the other hand, international comparisons may allow us to understand what might occur in future epidemiological contexts.

Nevertheless, this study presents some limitations. First, by recruiting participants through two web panels, the population samples were not probabilistic and were restricted to internet-users. Generalisation of the results should be interpreted in consequence. The mean response rate was considerably low. Previous Canadian studies using the same Canadian panel had response rates around 20 to 25\% (Léger \& Marketing, personal communication). A wide variety of factors are known to affect the response rate of web surveys, such as the methods of delivery [67]. For this study, the firm which administered the survey closed the survey access when 400 participants had completed the survey in a region, which took three days in Montérégie (response rate of $8.3 \%$ ) compared to 12 days in Neuchâtel (response rate of 36\%). A longer response period, especially in Montérégie, might have led to a better response rate. Though, these response rates depend in fact on the number of people who were initially contacted (5,222 in Montérégie vs 1,233 in Neuchâtel), and the mean response rate should be considered with regards to the recruitment process.

Secondly, all participants read a descriptive text before answering questions pertaining to perception. This was a strategic decision implemented in the study design with the objective of increasing the number of eligible respondents, particularly in Montérégie, where we expected that the majority of residents would not know enough about LD to complete the survey. But the content of this text may have altered participants' perception and consequently, may have biased their 'true' perception (i.e. the perception they would have had without reading the text, influenced by the information they already had about the disease).

Another limitation is the cross-sectional design of this study. Measures of risk perception, such as psychometric variables, can change rapidly over time [63]. Future work should include additional administrations of the risk perception questionnaire in the same regions in order to provide insights on the temporal evolution of risk perception and their determinants in both populations, and to allow confirmation of the risk perception factor structures.

Finally, regression models revealed interesting determinants in both regions, but explained only $12 \%$ and $11 \%$ of the variance in Montérégie and Neuchâtel, respectively.
Even if these percentages are low, they are consistent with other psychometric studies of risk perception [39]. When interpreting the multivariate analysis, we must keep in mind that several other possible unmeasured factors may have an impact on risk perception.

\section{Conclusion}

This study underlined significant differences between the two populations of Montérégie and Neuchâtel and between the general public and their regional experts, and demonstrated interesting trends within these populations, which are important elements to consider when planning and implementing LD prevention activities. Results revealed the need to strengthen and maintain LD risk communication in both regions and may help to prioritize target groups for enhanced communication about LD risk, for example men of 18-34 years of age, who may be more frequently exposed through outdoors activities, tend to have a poorer level of knowledge of LD as well as a lower perception of risk. The findings of this study also reveal the importance of monitoring risk perception in the target population, as it is determined by various dynamic factors that vary according to specific contexts, and as risk perception of the general public tends to differ from that of experts. Moreover, re-assessing risk perception over time (for example after communication campaigns) or across regions likely to have heterogeneous beliefs about LD should be considered in order to better align public health preventive actions for LD with underlying determinants and to enhance the efficacy of these actions.

\section{Competing interests}

The authors declare that they have no competing interests.

\section{Authors' contributions}

CA conceived and designed the study and drafted the manuscript. AR and PM helped in the design and statistical analyses. LG helped in the conception of the study and in the design of the survey. FM, JPW and DB helped in the conception of the study. All authors read, revised and approved the final manuscript.

\section{Acknowledgements}

The authors would like to acknowledge Guy Beauchamp and Valérie Hongoh for assistance with this study, as well as experts from Québec and Switzerland for their participation in this project. Funding was provided by the Fonds de la recherche du Québec, the Public Health Agency of Canada, the 4P Training program in health promotion, prevention and public policy, and the Ministère de l'Éducation, des Loisirs et des Sports du Québec.

\section{Author details}

${ }^{1}$ Groupe de Recherche en Épidémiologie des Zoonoses et Santé Publique (GREZOSP), Pavillon de la santé publique, Faculté de médecine vétérinaire, Université de Montréal, CP 5000, Saint-Hyacinthe J2S 7C6, Québec, Canada. ${ }^{2}$ Laboratory for Foodborne Zoonoses, Public Health Agency of Canada, CP 5000, Saint-Hyacinthe H2S 7C6, Québec, Canada. ${ }^{3}$ Laboratoire

d’Eco-Epidémiologie, Institut de Biologie, Université de Neuchâtel, 11 Emile-Argand, CP 158, 2009 Neuchâtel, Suisse. ${ }^{4}$ Institut national de santé publique du Québec, 1255 Beauregard, Longueuil J4K 2M3, Québec, Canada. ${ }^{5}$ Groupe d'étude et de recherche en analyse de la décision (GERAD), 3000 Côte-Sainte-Catherine, Montréal H3T 2A7, Québec, Canada. 
Received: 29 September 2014 Accepted: 11 December 2014 Published: 18 December 2014

\section{References}

1. WHO: Lyme borrelioses in Europe: Influences of Climate and Climate Change, Epidemiology, Ecology and Adaptation Measures. Denmark: World Health Organisation; 2006:35.

2. Nadelman RB, Wormser GP: Lyme borreliosis. Lancet 1998, 352(9127):557-565.

3. Centers for disease control and prevention. [http://www.cdc.gov/media/ releases/2013/p0819-lyme-disease.html]

4. Bourre-Tessier J, Milord F, Pineau C, Vinet E: Indigenous Lyme disease in Quebec. J Rheumatol 2011, 38(1):183.

5. Ogden NH, Bouchard C, Kurtenbach K, Margos G, Lindsay LR, Trudel L, Nguon S, Milord F: Active and passive surveillance and phylogenetic analysis of Borrelia burgdorferi elucidate the process of Lyme disease risk emergence in Canada. Environ Health Perspect 2010, 118(7):909-914

6. Gerster JC, Guggi S, Perroud H, Bovet R: Lyme arthritis appearing outside the United States: a case report from Switzerland. Br Med J (Clin Res Ed) 1981, 283(6297):951-952

7. Swiss Federal Public Health Office: La borréliose de Lyme: Enquête Sentinella 2008 à 2010. Bulletin de l'Office fédéral de la santé publique 2011 17 octobre 2011(42):895-898.

8. Jouda F, Perret JL, Gern L: Density of questing Ixodes ricinus nymphs and adults infected by Borrelia burgdorferi sensu lato in Switzerland: spatio-temporal pattern at a regional scale. Vector Borne Zoonotic Dis 2004, 4(1):23-32

9. Schuler M, Zimmermann H, Altpeter E, Heininger U: Epidemiology of tick-borne encephalitis in Switzerland, 2005 to 2011. Euro Surveill 2014, 19(13):1-7.

10. Piesman J, Gern L: Lyme borreliosis in Europe and North America. Parasitology 2004, 129(Suppl):S191-S220.

11. Piesman J, Eisen L: Prevention of tick-borne diseases. Annu Rev Entomol 2008, 53:323-343.

12. Finch C, Al-Damluji MS, Krause PJ, Niccolai L, Steeves T, O'Keefe CF, Diuk-Wasse MA: Integrated assessment of behavioral and environmental risk factors for Lyme disease infection on Block Island, Rhode Island. PLoS One 2014, 9(1):e84758.

13. Lane RS, Manweiler SA, Stubbs HA, Lennette ET, Madigan JE, Lavoie PE: Risk factors for Lyme disease in a small rural community in northern California. Am J Epidemio/ 1992, 136(11):1358-1368.

14. Smith G, Wileyto EP, Hopkins RB, Cherry BR, Maher JP: Risk factors for lyme disease in Chester County, Pennsylvania. Public Health Rep 2001, 116(Suppl 1):146-156.

15. Malouin R, Winch P, Leontsini E, Glass G, Simon D, Hayes EB, Schwartz BS: Longitudinal evaluation of an educational intervention for preventing tick bites in an area with endemic lyme disease in Baltimore County, Maryland. Am J Epidemio/ 2003, 157(11):1039-1051.

16. Vazquez M, Muehlenbein C, Cartter M, Hayes EB, Ertel S, Shapiro ED: Effectiveness of personal protective measures to prevent Lyme disease. Emerg Infect Dis 2008, 14(2):210-216.

17. Mowbray F, Amlot R, Rubin GJ: Ticking all the boxes? A systematic review of education and communication interventions to prevent tick-borne disease. Vector Borne Zoonotic Dis 2012, 12(9):817-825.

18. Gray JS, Granstrom M, Cimmino M, Daniel M, Gettinby G, Kahl O, Jaenson TG, Jongejan F, Korenberg E, O'Connell S: Lyme borreliosis awareness. Zentralbl Bakteriol 1998, 287(3):253-265.

19. Cartter ML, Farley TA, Ardito HA, Hadler JL: Lyme disease preventionknowledge, beliefs, and behaviors among high school students in an endemic area. Conn Med 1989, 53(6):354-356.

20. Valente SL, Wemple D, Ramos S, Cashman SB, Savageau JA: Preventive behaviors and knowledge of tick-borne illnesses: results of a survey from an endemic area. J Public Health Manag Pract 2014, 00(00):1-8.

21. Heller JE, Benito-Garcia E, Maher NE, Chibnik LB, Maher CP, Shadick NA Behavioral and attitudes survey about Lyme disease among a Brazilian population in the endemic area of Martha's Vineyard, Massachusetts. J Immigr Minor Health 2010, 12(3):377-383.

22. Mowbray F, Amlot R, Rubin GJ: Predictors of protective behaviour against ticks in the UK: a mixed methods study. Ticks Tick Borne Dis 2014, 5(4):392-400.

23. McKenna D, Faustini Y, Nowakowski J, Wormser GP: Factors influencing the utilization of Lyme disease-prevention behaviors in a high-risk population. J Am Acad Nurse Pract 2004, 16(1):24-30.
24. Beaujean DJ, Gassner F, Wong A, van Steenbergen JE, Crutzen R, Ruwaard $D$ : Determinants and protective behaviours regarding tick bites among school children in the Netherlands: a cross-sectional study. BMC Public Health 2013, 13:1148.

25. Beaujean DJ, Bults M, van Steenbergen JE, Voeten HA: Study on public perceptions and protective behaviors regarding Lyme disease among the general public in the Netherlands: implications for prevention programs. BMC Public Health 2013, 13:225.

26. Phillips CB, Liang MH, Sangha O, Wright EA, Fossel AH, Lew RA, Fossel KK, Shadick NA: Lyme disease and preventive behaviors in residents of Nantucket Island, Massachusetts. Am J Prev Med 2001, 20(3):219-224.

27. Gould LH, Nelson RS, Griffith KS, Hayes EB, Piesman J, Mead PS, Cartter ML: Knowledge, attitudes, and behaviors regarding Lyme disease prevention among Connecticut residents, 1999-2004. Vector Borne Zoonotic Dis 2008, 8(6):769-776.

28. Herrington JE Jr, Campbell GL, Bailey RE, Cartter ML, Adams M, Frazier EL, Damrow TA, Gensheimer KF: Predisposing factors for individuals' Lyme disease prevention practices: Connecticut, Maine, and Montana. Am J Public Health 1997, 87(12):2035-2038.

29. Herrington JE: Risk perceptions regarding ticks and Lyme disease: a national survey. Am J Prev Med 2004, 26(2):135-140.

30. Sjöberg LMB, Rundmo T: Explaining Risk Perception. An Evaluation of the Psychometric Paradigm in Risk Perception Research. Trondheim: Rotunde; 2004.

31. Conner M, Norman P: Predicting Health Behaviour. Open University Press: 2005

32. Shadick NA, Daltroy LH, Phillips CB, Liang US, Liang MH: Determinants of tick-avoidance behaviors in an endemic area for Lyme disease. Am J Prev Med 1997, 13(4):265-270.

33. Brewer NT, Weinstein ND, Cuite $C L$, Herrington JE: Risk perceptions and their relation to risk behavior. Ann Behav Med 2004, 27(2):125-130.

34. Brewer NT, Chapman GB, Gibbons FX, Gerrard M, McCaul KD, Weinstein ND: Meta-analysis of the relationship between risk perception and health behavior: the example of vaccination. Health Psychol 2007, 26(2):136-145

35. Slovic P: Perception of risk. Science 1987, 236(4799):280-285.

36. Slovic P: Perception of risk: reflections on the psychometric paradigm. In Social Theories of Risk. Edited by Krimsky S, Golding D. Santa Barbara: Praeger; 1992:117-152.

37. Slovic P: The Perception of Risk. London: Earthscan; 2000

38. Sjoberg L: Risk perception: experts and the public. Eur Psychol 1998, 3(1):1-12.

39. Sjoberg L: Factors in risk perception. Risk Anal 2000, 20(1):1-11.

40. Kasperson RE, Kasperson JX: The social amplification and attenuation of risk. Ann Am Acad Polit Ss 1996, 545:95-105.

41. Chauvin B, Hermand D, Mullet E: Risk perception and personality facets. Risk Anal 2007, 27(1):171-185.

42. Nahimana I, Gern L, Péter O, Praz G, Moosmann Y, Francioli P: [Epidemiology of Lyme borreliosis in French-speaking Switzerland] Schweiz Med Wochenschr 2000, 130(41):1456-1461.

43. Moosmann Y, Brossard M, Raeber P, Gern L: Estimated Lyme borreliosis incidence in the canton of Neuchâtel (Switzerland). Bulletin de la Société neuchâteloise des Sci Naturelles 2012, 132:47-56.

44. Ferrouillet C, Lambert L, Milord F: Consultation sur l'état actuel de la surveillance des zoonoses au Québec et son adéquation avec les changements climatiques et écologique. Québec: Institut national de santé publique du Québec; 2012:147

45. Garvin JH, Gordon TF, Haignere C, Ducette JP: Development of a public health assessment tool to prevent Lyme disease: tool construction and validation. Perspect Health Inf Manag 2005, 2:11.

46. Serafin D: Lyme disease risk reduction: perceptions and behaviors in a Connecticut community. Master Thesis. Southern Connecticut State University, Department of Public Health; 2004.

47. Jouda F, Perret JL, Gern L: Ixodes ricinus density, and distribution and prevalence of Borrelia burgdorferi sensu lato infection along an altitudinal gradient. J Med Entomol 2004, 41(2):162-169.

48. Léger Marketing. [http://leger360.com/en-CA/home.asp]

49. Swiss Statistics. [http://www.bfs.admin.ch/bfs/portal/fr/index/themen/01/ 02/blank/key/raeumliche_verteilung/kantone_gemeinden.html]

50. Institut de la statistique du Québec. [http://www.stat.gouv.qc.ca/ statistiques/population-demographie/structure/ra_total.htm]

51. Aenishaenslin C, Hongoh V, Cisse HD, Hoen AG, Samoura K, Michel P, Waaub JP, Belanger D: Multi-criteria decision analysis as an innovative 
approach to managing zoonoses: results from a study on Lyme disease in Canada. BMC Public Health 2013, 13:897.

52. Centre national de référence pour les maladies transmises par les tiques. [http://www2.unine.ch/cnrt/page-11421.html]

53. Clopper C, Pearson E: The use of confidence or fiducial limits illustrated in the case of the binomial. Biometrika 1934, 26(4):404-413.

54. Fabrigar L, Wegener D: Exploratory Factor Analysis. Oxford: Oxford University Press; 2012.

55. Fabrigar L, Wegener D, MacCallum R, Strahan E: Evaluating the use of exploratory factor analysis in psychological research. Psychol Methods 1999, 4(3):272-299

56. Tabachnick B, Fidell L: Using Multivariate Statistics. 6th edition. Boston: Pearson Education Inc:; 2007.

57. Kaiser HF, Rice J: Little jiffy, mark 4. Educ Psychol Meas 1974, 34(1):111-117.

58. Tavakol M, Dennick R: Making sense of Cronbach's alpha. Int J Med Educ 2011, 2:53-55.

59. Armstrong PM, Brunet $L R$, Spielman A, Telford SR 3rd: Risk of Lyme disease: perceptions of residents of a Lone Star tick-infested community. Bull World Health Organ 2001, 79(10):916-925.

60. Shepperd JA, Carroll P, Grace J, Terry M: Exploring the causes of comparative optimism. Psychol Belg 2002, 42(1-2):65-98

61. Weinstein ND: Unrealistic optimism about susceptibility to health problems: conclusions from a community-wide sample. J Behav Med 1987, 10(5):481-500.

62. Decker DJ, Evensen DT, Siemer WF, Leong KM, Riley SJ, Wild MA, Castle KT, Higgins $C L$ : Understanding risk perceptions to enhance communication about human-wildlife interactions and the impacts of zoonotic disease. ILAR J 2010, 51(3):255-261.

63. Marsden PV, Wright JD: The Handbook of Survey Research. 2nd edition. Bingley: Emerald Group Publishing; 2010 .

64. Henson RK, Roberts JK: Use of exploratory factor analysis in published research - Common errors and some comment on improved practice. Educ Psychol Meas 2006, 66(3):393-416.

65. Gustafson PE: Gender differences in risk perception: theoretical and methodological perspectives. Risk Anal 1998, 18(6):805-811.

66. Deery HA: Hazard and risk perception among young novice drivers. J Safety Res 1999, 30(4):225-236.

67. Fan $W$, Yan Z: Factors affecting response rates of the web survey: a systematic review. Comput Hum Behav 2010, 26(2):132-139.

doi:10.1186/1471-2458-14-1298

Cite this article as: Aenishaenslin et al:: From Lyme disease emergence to endemicity: a cross sectional comparative study of risk perceptions in different populations. BMC Public Health 2014 14:1298.

\section{Submit your next manuscript to BioMed Central and take full advantage of:}

- Convenient online submission

- Thorough peer review

- No space constraints or color figure charges

- Immediate publication on acceptance

- Inclusion in PubMed, CAS, Scopus and Google Scholar

- Research which is freely available for redistribution

Submit your manuscript at www.biomedcentral.com/submit 